Australian Journal of Educational Technology

\title{
Open learning and critical reflection: Implications for OTEN
}

\section{Tim Miles}

This article examines the relationship between open learning and critical reflection and the implications of this for OTEN. OTEN (Open Training and Education Network) is the TAFE institution which was formerly known as the External Studies College of TAFE and which in 1990 changed its name to the Open College and more recently to OTEN. The fact that the word "open" is now incorporated in its name is significant in so far as its role is perceived to have changed from distance to open education.

Some general issues which will be considered include:

\section{The meaning of "open learning"}

Distance learning as presently practised in OTEN is presumably only one factor in the concept of open learning. To what extent does OTEN actually implement the principles of open reaming in its provision of distance learning? A narrow definition of open learning being just an extension of distance learning may lead to a loss of potential for what could be a major change in adult education in general. Some of the problems associated with distance learning to date include bureaucratic restraints in the forms of timetabling, enrolment forms and dissemination of massed produced material. To what extent does open learning overcome these problems?

\section{The relationship of open learning to critical reflection}

A critical reflective approach gives greater meaning to the position of the learner in the educational process. Does this approach lead the way to the kind of attitudes to learning which overcome the barriers imposed by the bureaucratic natures of educational institutions such as OTEN? Or is critical reflection a relic of the 70 s and 80 s which does not fit in with the aims of the economic rationalists of the 90 s to achieve economic prosperity and international competitiveness? 


\section{The role of the teacher and teacher training in open learning}

Should teacher attitudes be consistent with a critical reflective approach to understand and implement open learning? Is there an inherent barrier to the adoption of these attitudes because of the bureaucratic and other restraints previously mentioned? Teacher training itself should be based on open learning principles if these are the principles which are to apply to the learners.

\section{The potential that open learning may provide greater equity in learning opportunities}

Does open learning provide greater access to educational opportunities to those who have been denied access by traditional education? Or will it maintain the existing status quo by providing education to those who are already socially advantaged to use it? The greater dependence of distance education on advanced technology, for instance, may result in the cost factor denying the less economically advantaged access to education.

\section{Open learning - What does it mean?}

"Open Learning" is a term which has been used to imply an openness for learning which has previously been lacking in traditional authoritarian means of education. Some of the meanings which are commonly attributed to it include:

(i) greater access to those previously denied access to education;

(ii) greater flexibility to the individual learner in the form of autonomous self directed learning;

(iii) less restriction on the formalities of education; and

(iv) a laissez faire attitude by the providers of education for the recipients of that education.

Lewis and Spencer (1986) state that at the heart of open learning is the individual learner and that traditional education has been inappropriate for the individual learner. Open learning lessens constraints and remove barriers for open learners by promoting such qualities as autonomy, independence and flexibility. It accordingly incorporates a stronger learner centred philosophy.

Thorpe (1988) defines the goals of open learning as:

(i) to increase the rate of participation in education and training, especially among groups with low rates of participation to date; and

(ii) to improve the quality and extent of learning achieved by those who do participate. 
There are accordingly two aspects which distinguish open learning from traditional distance learning . One aspect is the provision of greater access to the educational institution and the other is the opportunity for greater flexibility of learning once the access has been obtained.

Concerning access, learners must have an educational background which enables them to deal with the literacy level of enrolment forms and administrative procedures before embarking on most of the courses offered by OTEN. The logo of "open for learning" implies that the doors of the college are open to all those who wish to learn. But in reality, some, because of previously disadvantaged educational backgrounds cannot get to the door in the first place.

Not only the forms of enrolment, but also the learning materials themselves that are required to be processed favour those who have come from fairly middle class and hence "literary" backgrounds. Westwood (1980) believes that because of the nature of forms and learning materials in distance education, the learner is placed in a position similar to that encountered in a classroom at school. This sociological aspect should be taken into account in the implementation of open learning programs if greater equity is to be achieved.

\section{How is open learning taught? - Means of communication}

This leads to an examination of the forms of communication used by institutions which offer open learning. The emphasis in traditional distance learning has been on mass produced written materials. To a certain extent this favours the learner who is used to written communication and this of course would include those from middle class backgrounds referred to by Westwood. With the move to open learning there is a tendency to use, in addition to mass produced written materials, advanced technology in the forms of teleconferencing, video conferencing, and computer assisted learning.

What must be questioned is whether these advanced forms of communication for adult education reinforce the present bias towards middles class learners as exists with mass produced written materials. On a practical level the more advanced the technology the more expensive it becomes for the learner In their initial stages the television, the video, and the computer were beyond the reach of many who could utilise their educational potential. With increase in use and popularity these items may have become cheaper but certainly it would have to be acknowledged that access to technology is still denied or limited in its availability to the less economically advantaged in the community.

Another aspect to be questioned is the continued use of mass produced written materials which is still a significant part of OTEN's communication with learners. This of course is cost effective in that material is produced 
on a one off basis to reach a large audience but inherent in this is a dichotomy for open learning. If materials are produced on such a large scale, or similarly if satellite programs are produced for a large audience, the potential to allow a student to achieve a stage of autonomous self directed learning may be minimalised.

By the production of mass learning materials do we have no more than a "production line" technique where there is less opportunity for openness than could be achieved in a face to face class for instance? The answer lies partly in the position the teacher places himself or herself in the distance education institution for which he works and the extent to which he or she can encourage open learning in students given the bureaucratic restraints of mass produced materials, timetables, and external exams.

Evans and Nation (1989) maintain that the print production processes in distance education resemble industrial production. This form of production of learning materials is based on behaviourist models of learning and distance teachers by necessity are required to engage with and conform to these sources of learning.

\section{Critical reflection}

To change the teacher attitude embedded in this behaviourist model requires a critical reflective approach such as that advocated by Stephen Brookfield. According to Brookfield (1987) many adults devise and conduct much of their informal learning without assistance from professional educators. Many people of different classes and ethnic backgrounds produce their own learning according to their needs and interests. This can range from hobbies such as fishing to an important event in their lives such as having a child. The quest for self directed learning, however, should not cease when they are engaged in more formal education.

It is here that distance education should take account of this self directed capacity of learners and incorporate the potential for this in its written materials. Evans and Nation (1989) state that recognising this capacity for self direction in learning is tantamount to recognising the potential of people to "shape and control their own destinies and the social conditions which surround them." (p.250)

How then does a teacher of distance education encourage a critical reflective approach in his or her learners? Limitations are of course the lack of immediacy available in a classroom such as facial and verbal expressions. However, as advocates of distance education have argued this can be overcome by the intimacy which can be achieved between the teacher and distance learner by the quality of written communication.

This two way written communication is what Holmberg (1986) refers to as "guided didactic conversation" (p.4). Although material may be written for 
a large faceless audience it should be written as if "conversing" with each learner individually. In addition to the way in which the material is written, the distance teacher's role is also crucial in his or her interaction with the learner.

An example of a distance teacher adopting a critical reflective approach is that of Helen Morda with distance librarian students at an Australian College of Advanced Education in South Australia. Morda (1989) allowed her students to prepare a structured journal rather than the more conventional forms of assessment. The journal required the students to investigate political, social and cultural events and trends rather than churn out predetermined facets of information. She acknowledged that this was a different task for her students because their educational history to date was in the passive learner tradition. Her conscious motive was to raise in her learners an awareness of the positions of libraries and librarians in society rather than their learning experience being the mere acquisition of technical information.

Morda's attempt at arousing a critical awareness in her students is consistent with Brookfield's espousal of critical reflection in the facilitation of learning. But to develop this awareness, the teacher as facilitator must present alternative interpretations of the learner's work lives, personal relationships, and views of the social and political world. It does not mean that the teacher tries to convert the student to accepting a new ideology but to provide the impetus to the student to play a more active and questioning role in his or her learning.

\section{Critical reflection and teaching at OTEN}

Here lies the challenge for the distance teacher. The dissemination of information in mass produced material does not lend itself to critical awareness. Teachers at OTEN are often restrained by:

(i) set curriculums and external exams;

(ii) the existing educational backgrounds of the learners which are contrary to a critical approach; and

(iii) lack of input into the printed materials which are often written by other teachers.

An approach such as that of Morda with her journals is not practical given these restraints. Students, to conform with the college requirements, must do a certain amount of predetermined assignments which are assessed by teachers. Most of them must also sit for an external exam in common with other students who have attended face to face colleges. A practical restraint on being innovative by requiring, or giving them the option to do 
a journal rather than assignments, is that they may be disadvantaged in the external exam compared to their face to face college counterparts.

What opportunities are provided by OTEN to its teachers to be innovative in their teaching in order to achieve open learning? OTEN's stated role in the implementation of open learning extends beyond the curriculum of its own courses to the curriculum of TAFE courses in general. The extent to which it achieves this role will depend on its ability to foster an awareness in the principles of open learning in those who will be responsible for its implementation, namely the teachers, instructional designers and educational materials' writers. Staff development then is crucial if any significant changes are to be achieved.

\section{Teacher anxieties and social defence mechanisms}

In devising staff development programs what are some of the anxieties OTEN can anticipate in teacher resistance to change to open learning? OTEN might take cognisance of what Boud (1981) refers to as "structural sources of resistance to change". According to him anyone advocating or trying to initiate independent learning on a significant scale will usually experience a wealth of objections and criticisms related to more fundamental issues. These issues include a reluctance by teachers to loose control to the learner and a corresponding reliance on bureaucratic formalities including rigid adherence to timetables and assessment criteria.

An interesting psychological explanation of this resistance to change in an institutional setting is that of Lyth (1988) in her study of the nursing profession. She explains that nurses adopt "social defence mechanisms" to overcome their anxiety at some of the unpleasant or new tasks which they are faced to confront. Instead of being creative and fulfilling their real capacity for concern, compassion and sympathy nurses often follow perceived roles of "efficiency" for fear of making mistakes. By following the rules and ritualistic practices of their profession, there is no need for nurses to feel personally responsible for their actions.

There is a tendency in other professions to follow the norms and expected ethos of the profession. In educational institutions, typical social defence mechanisms that teachers may rely on are their perceived roles to comply with the form filling, paper checking and materials distribution. While doing so they can avoid anxiety about how to engender true open learning. By allowing students more independence, there is the subconscious fear of losing control which is manifested in the teacher's power over the learner's ultimate assessment.

The lesson for OTEN in implementing and adhering to open learning principles is to recognise the existence of teacher anxiety about interacting with learners in new and more challenging ways. The way in which this 
anxiety is dispelled by way of staff development will be a significant factor in OTEN's success as a major provider of open learning.

\section{Conclusion}

This report has examined a number of issues that surround the principles of "open learning" especially in so far as they relate to OTEN. A significant aspect of this has been the change from distance education to what is being increasingly referred to as open learning. The importance of the change in emphasis from distance to open learning is reflected in the change in name of what was previously referred to as an external studies college to one in which the word "open" is included in its designation.

Some of the problems associated with distance education, such as bureaucratic and administrative restraints, have led to the adoption of open learning principles. The success of the implementation of these principles will depend on the extent to which these traditional problems are overcome. An examination of the concept of critical reflection has given an insight as to why these problems existed in the first place and how they can be avoided. As long as the provision of distance education continues to be seen as similar to industrial production consistent with economic rationalism and behaviourist principles, then the problems will remain.

However, a critical reflective stance should favour the individual uniqueness and potential of the learner rather than he or she being a faceless product of an industrial enterprise. A critical awareness of the learner's position in society and the workplace is what open learning should be achieving. To do this, it is tantamount that the teacher be critically aware of his or her role in open learning and that, in teacher training, cognisance be given to the importance of this awareness.

To be successful in its role as a provider of open learning OTEN will require more than token adherence to the aims stated in its logo of being "open for learning". Unless there is a genuine attempt to understand and implement the values of open learning amongst its teachers and learners, then it is doubtful whether the qualities expected of them will be any different to those produced by traditional forms of education. Critical reflection is an approach to learning which is consistent with these values and qualities.

\section{References}

Boud, D. (Ed) (1981). Developing Student Autonomy in Learning. Kogan Page: London.

Brookfield, S. D. (1987). Understanding and Facilitating Adult Learning. Jossey-Bass, San Francisco.

Evans, T. and Nation, D. (Eds) (1989). Critical Reflections on Distance 
Education. The Falmer Press, East Sussex, England.

Holmberg, B. (1986). Growth and Structure of Distance Education. Croom Helm, Kent, England.

Lewis, R. and Spencer, D. (1986). What is Open Learning? National Council for Educational Technology, London.

Lyth, I. M. (1988). Containing Anxiety in Institutions. Free Association Books, London.

Morda, H. (1989). Using journals to encourage critical thinking at a distance. In Evans, T. and Nation, D. (Eds), Critical Reflections on Distance Education. The Falmer Press, East Sussex, England.

Scriven, B. (1991). Distance education and open learning - Implications for professional development and retraining. Distance Education, 12(2), 297305.

Thorpe, M. (1988). Evaluating Open and Distance Learning. Longman, Essex, England.

Westwood, S. (1980). Adult education and the sociology of education - an exploration. In Thompson, J. L. (Ed), Adult Education for a Change.

Hutchinson, London.

Please cite as: Miles, T. (1994). Open learning and critical reflection: Implications for OTEN. Australian Journal of Educational Technology, 10(1), 19-26. http: / / www.ascilite.org.au/ajet/ajet10/miles.html 